\title{
Study of the properties of drinking water for Kirkuk city and its pollution in some areas
}

\author{
Iman Hussein Zainulabdeen \\ Kirkuk Technical Institute, Kirkuk, Iraq
}

\begin{abstract}
This study was conducted to demonstrate the difference between drinking water quality for seven different areas of Kirkuk city with the treatment water in the main and three sub storages tanks, affected with drinking water pipe lines, supplying system Alternate and continuous and also pipes across the construction work's areas. The physical and chemical properties (turbidity, $\mathrm{pH}$, conductivity, Alkalinity, Total hardness, calcium, magnesium, chloride, sulfate, TDS (Total dissolve solids), TSS (Total suspended solids), sodium and potassium) for raw water and treated water in the Storages in addition to the supplying water from seven different areas in Kirkuk were analyzed, samples taken at a rate nine times during the month of March. Results showed that Drinking water of Dumez, Wasti, Shorja, Imam Qasim and Arubaa polluted with turbidity with an average levels of $(8.68,6.04,7.41,6.95,7.64)$ NTU respectively, over the limit allowed by IBWA (International Bottled Water Association), 2012 and WHO (World Health Organization), 2006. The turbidity in the main and sub storages have reached $(4.04,4.09,4.47,4.16)$ NTU respectively, while other physical and chemical properties were within the allowed limits for human use. The pollution in those areas caused by the alternative supplying system of treatment water and it has negative impact on the pipelines, it includes constriction work in areas also where pipelines exist.
\end{abstract}

\section{Introduction}

In large drinking water distribution networks, water needs to move in a large distances from the treatment units to the storage units and then to the consumer through a major and sub distribution networks, the problem is that this process will affect the stomach drinking water quality, which is an important issue that has attracted the attention of many governments and centers research in the world [1] . This problem may occur due to rarity of water pressure inside the pipelines, [2] it indicates that the increase of transferred water's pressure in the pipeline and non - stability causes Water Turbidity and erosion in the pipes. The corrosion or decomposition in the pipe results, an increase in the proportion of metals and organic substances in the water, which in turn causes an increase in the number of microorganisms exceeding the allowable limit (1-10 times) and poses a threat to consumer health [3].

Though the amount of corrosion also depends on the quality of the materials used in water pipeline and storage tanks. [4] They have studied this kind of effects using pipes made of PVC (Polyvinyl Chloride), HDPE (High Density Polyethylene) and GRP (Glass Fiber
Reinforced Polyester) in addition to the effect of small bottle waters ( plastic ) on the quality of drinking water, they noted the possibility of leaks of some organic ingredients causing a change in taste, color and smell as well as the increase in bacterial growth in it, [5] e Comparing the effect of the two types of metal and plastic water pipes quality in Honduras, they found an increase in the proportion of iron at the very first flow of water and an increase in the microorganisms in the metal pipe when compared to plastic pipes. it showed an increase in concentrations of manganese, lead and dark colours.

In another research, [6] study water samples for 40 sites in Dhahran in Saudi Arabia, he noted an increase of lead's component in the water plastic pipelines and increase of the copper component in the copper water pipes, [7] He pointed a change in water taste and smell to an unacceptable degree to the consumer because of the interaction of water with piping components. In another study, [8] he observed the discoloration of water that has been collected from copper pipes (with ages serving more than six years) It was blue-green colored due to the corrosion.

It has been observed that the breakage and cracking in buried pipelines under various depths from the surface 
of the soil and defect in the joints of the pipes cause water pollution as will as leakage of large amounts of water 17\% in 1997 in large and medium-sized cities [9]. The contaminated soil material surrounding the pipe increase the pollution in the rainy days at construction work place, the passage of networks near the sewage and industrial area networks [10]

the time period of using pipeline contributes the cracks occurrence in the walls [11]. It indicates that the age of plastic pipes affects the extent of shock resistance to the walls of the pipes caused by the movement of water within the pipes, this effect has been shown since the first time usage, Vulnerability is up to the amount of $80 \%$ compared with normal .

In general, [12] he studied failure rate in the pipes used to deliver water in the United Kingdom Building through 40 years ( which compares the types of pipes metal, aspect, plastic P.V.C. and ductile plastic P.E.), he noted that the highest percentage occurred in the metal pipe compared with PVC pipe .

Various pipe-related incidents that could occur in urban areas are mostly related to the lack of information on pipelines and underground management. With regard to water supply, the torn pipes resulting from these accidents lead to different leaks. These fatal accidents lead to increase in direct and indirect injuries[13].Kirkuk province is situated to the northeast of the city of Baghdad, with a population of 940,000 thousand people. Almost $65 \%$ of them live in the city of Kirkuk, according to unofficial statistics of 2009 , the city of Kirkuk is equipped with clean water from the Kirkuk general water treatment project based on Bottom Zab River as well as water wells adopted in some modern areas that have not been linked to a network pipeline after water treatment units when there are high levels of pollution in the water of those wells .

\section{Materials and methods}

Water samples collected from 12 different location including main water source for project of liquidation ( Zab Al-asfal river), main water storage tank (SGT1) after treatment, water storage tanks (SGT2, SGT3, SGT4) located to the north east of the city of Kirkuk and seven residential areas distributed within the city of Kirkuk ( Al-muhafatha, Imam Qasim, Shorja ) which are fed from SGT2, ( Arubaa, Tesien ) which are fed from SGT3, ( Dumez, Al-wasti ) that are fed from SGT4 (Figure1,2). Water samples collected nine times repeatedly and all tested at different dates, areas starting from (01/03/2014 - 02/04/2014).

Since the supply of water to most residential areas in the city of Kirkuk is periodic from day to day, it was considered that samples will be taken 15 minutes after the beginning of the flow of water in the pipeline in anticipation of not collecting samples of stagnant water inside pipes after the interruption of flow in the previous processing period, 2 liters of each sample were taken in pre-sterilized glass containers in the laboratory, samples transferred to the laboratory and stored at a temperature of $4 \mathrm{C}^{\circ}$ away from light.

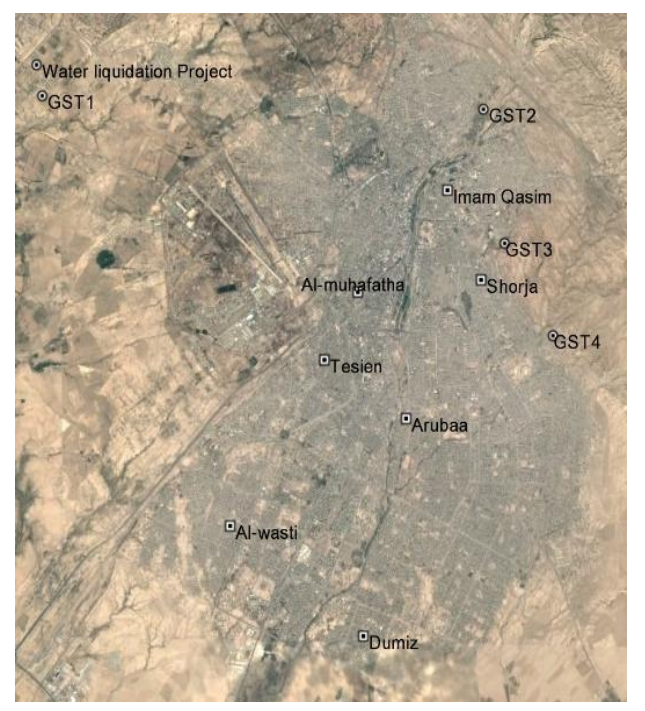

Figure 1 : Distribution of sampling areas within the city of Kirkuk

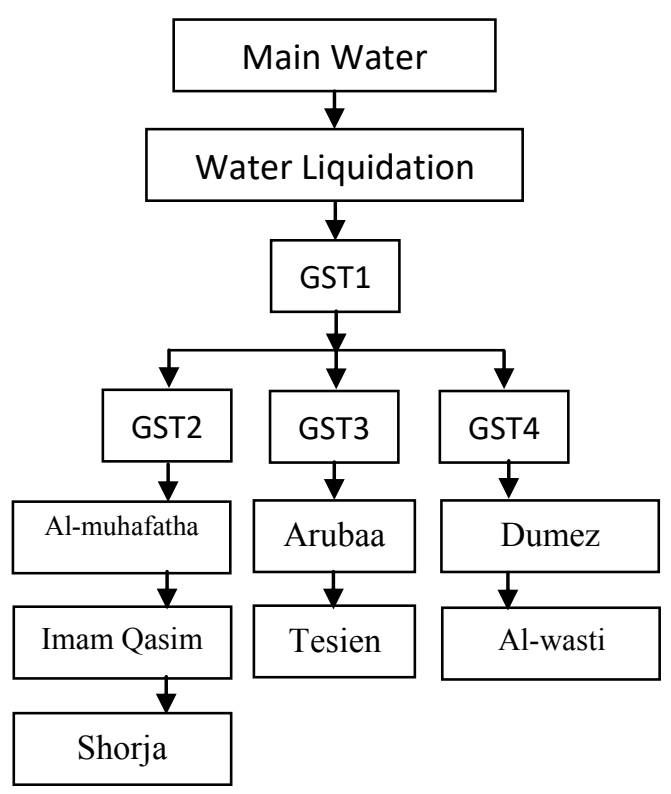

Figure 2 : Distribution plan of the water pipeline inside the city of Kirkuk

Some physical and chemical analysis were conducted in the laboratories of the Directorate of Water in Kirkuk, where measurements were taken as indicators of the amount of pollution in the water, such as (Turbidity, $\mathrm{pH}, \mathrm{ECu}$, Total Dissolved Solid (T.D.S.), Total 
Soluble Substances (T.S.S.), Hardness, Alkalinity as $\mathrm{CaCo}_{3}$, Calcium, Magnesium, Chloride, Sulfate, Sodium and potassium).

$\mathrm{PH}$ and E.C.u were measured using a $\mathrm{pH}$ meter and a conductivity meter depending on the method used by [14].

1. Positive ions: The method used was adopted before [15] to estimate calcium, sodium, potassium and magnesium.

2. Negative ions: These include sulphates, carbonates and chlorides, It was estimated by following the method used before [15].

3. Total severity: It was estimated using the method described by [15].

4. Total dissolved salts: It was calculated by the sum of negative and positive ions.

5. Inverter: It was measured using a Hach2100.

6. Suspended Materials: It was calculated from the results obtained for total solids and total soluble substances by the following equation:

TSS $=$ Total solids - Total dissolved

\section{Results and discussion}

Table 1,2 shows differences in the values of physical and chemical analysis in the tested water samples for all the study area inside the city of Kirkuk, in addition to the main water tanks GTS1, GTS2, GTS3 and GTS4 Which distributes water networks to different areas of study.

Table 1: Average values of physical analysis of water samples tested

\begin{tabular}{|c|c|c|c|c|c|c|}
\hline $\begin{array}{c}\text { Sampling } \\
\text { area }\end{array}$ & 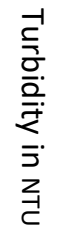 & 꾸 & 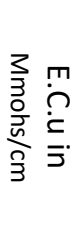 & $\begin{array}{l}\overrightarrow{1} \\
\dot{0} \\
\text { in } \\
\text { ơ } \\
\stackrel{-}{=}\end{array}$ & $\begin{array}{l}\text {-1 } \\
\text { in } \\
3 \\
30 \\
=0\end{array}$ & 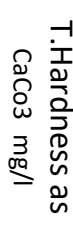 \\
\hline Zab river & 29.9 & 7.59 & 393.5 & 245.5 & 65.22 & 172 \\
\hline GST1 & 4.04 & 7.53 & 373.3 & 239.1 & 47.25 & 164 \\
\hline GST2 & 4.09 & 6.55 & 381.1 & 237.3 & 43.25 & 172 \\
\hline Almuhafatha & 4.69 & 7.07 & 380.7 & 240.2 & 45.87 & 170 \\
\hline Imam Q. & 6.95 & 7.07 & 372.3 & 238.2 & 47.33 & 171 \\
\hline Shorja & 7.41 & 6.78 & 388.7 & 253.8 & 47.22 & 170 \\
\hline GST3 & 4.47 & 7.30 & 383.6 & 234.8 & 43.25 & 171 \\
\hline Arubaa & 7.64 & 6.91 & 381.6 & 226.7 & 41.62 & 170 \\
\hline Tesien & 4.09 & 6.95 & 380.6 & 231.8 & 44.12 & 164 \\
\hline GST4 & 4.16 & 7.30 & 375.7 & 237.0 & 36.62 & 171 \\
\hline Dumez & 8.68 & 6.85 & 392.7 & 236.3 & 39.50 & 172 \\
\hline Al-wasti & 6.04 & 6.81 & 400.3 & 233.5 & 46.12 & 168 \\
\hline IBWA-WHO & 5.00 & $\begin{array}{l}6.5- \\
8.5 \\
\end{array}$ & $\begin{array}{c}70- \\
300 * * \\
\end{array}$ & 500 & 1000 & 500 \\
\hline \multicolumn{7}{|c|}{$\begin{array}{l}\text { [16](WHO,1996)=World Health Organization } \\
*[17](\text { IBWA })=\text { International Bottled Water Stander Quality } \\
* *[18](\text { FAO })=\text { Food \& Agriculture Organization }\end{array}$} \\
\hline
\end{tabular}

Table 2: Average value of chemical \& Percentage of component ratios of water samples tested

\begin{tabular}{|c|c|c|c|c|c|c|c|}
\hline 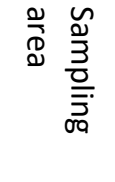 & 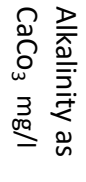 & 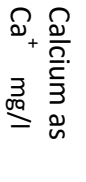 & 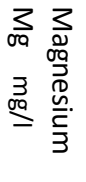 & 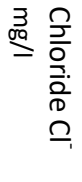 & 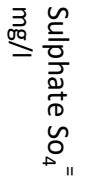 & 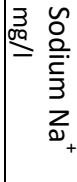 & 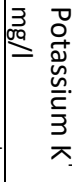 \\
\hline Zab river & 133 & 42.3 & 16.4 & 15.8 & 44.8 & 7.3 & 1.6 \\
\hline GST1 & 130 & 42.7 & 15.0 & 16.5 & 48.5 & 7.3 & 1.5 \\
\hline GST2 & 129 & 41.0 & 16.7 & 15.6 & 46.1 & 7.3 & 1.5 \\
\hline Al-muh. & 133 & 42.8 & 15.6 & 17.3 & 41.3 & 7.4 & 1.5 \\
\hline Imam Q. & 134 & 41.5 & 16.4 & 16.3 & 39.5 & 7.2 & 1.5 \\
\hline Shorja & 139 & 43.5 & 15.6 & 18.9 & 42.9 & 7.1 & 1.6 \\
\hline GST3 & 130 & 41.5 & 15.8 & 15.7 & 41.5 & 7.5 & 1.5 \\
\hline Arubaa & 132 & 42.0 & 15.2 & 16.7 & 42.0 & 7.0 & 1.5 \\
\hline Tesien & 131 & 40.5 & 16.6 & 17.8 & 40.0 & 6.6 & 2.0 \\
\hline GST4 & 130 & 42.5 & 14.7 & 16.6 & 47.5 & 7.3 & 1.5 \\
\hline Dumez & 143 & 40.6 & 17.6 & 16.4 & 39.6 & 7.0 & 1.7 \\
\hline Al-wasti & 133 & 40.9 & 15.8 & 16.9 & 41.4 & 7.2 & 1.5 \\
\hline $\begin{array}{l}\text { IBWA- } \\
\text { WHO }\end{array}$ & $\begin{array}{l}125- \\
200^{*}\end{array}$ & 50 & 50 & 250 & 250 & 200 & $10^{*}$ \\
\hline
\end{tabular}

The highest value of turbidity was found in the areas of (Dumez, Al-Wasati, Shorja, Imam Qassem and Arubaa), with a ratio of $(8.68,6.04,7.41,6.95,7.64)$ $\mathrm{mg} / \mathrm{L}$ respectively, exceeding the limit of [16]\&[17] .

Note that the amount of turbidity in the collection tank of the liquidation project and three major feeder reservoirs of the city were between ( $4.04-4.47$ ) NTU , on the other hand when compared turbidity between sampling dates, ( Figure 3 ).

This discrepancy may be due to the periodic water distribution system within the residential areas in the city of Kirkuk, which depends on supplying the residents from one day to another, where the interruption of the flow of water inside the pipes leads to the deposition of the contents of the insoluble and cumulatively on the one hand, and the variation of water pressure moment of flow within the tubes and the sediments contained in them increase the rate of turbidity in the supplied water, which is clearly visible in the first supply of the water flow to the consumer and may continue for a few hours, and the turbidity ratios in the areas of Tesien and the province have recorded low rates and within the limit of the consumer (4.09 and 4.69) NTU, it may be happen, that both regions are provided water per day without the adoption of deliberation system. 


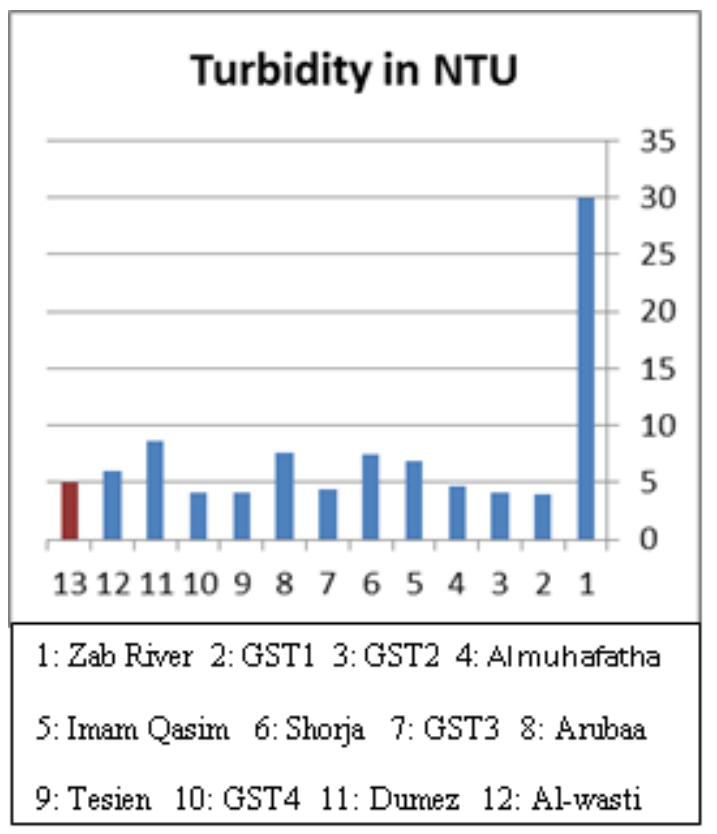

Figure 3 : Turbidity in NTU for water samples tested.

The highest rate of turbidity in the Dumez area, which is supplied daily with water, exceeded the limit of 8.68 NTU. When asked about the problem from the specialists and the residents of the area, the water pipes were found damaged in the area due to the construction work in the area. two years ago.

$\mathrm{PH}$ values in Table (1) showed no significant differences between the sampling sites and ranged between $(6.3-8.1)$. They were within the permissible range of human use and were not affected during the transfer of water from the project to the consumer during the pipeline.

Also, it was noted in (Tables 1) that the electrical conductivity values E.C.u rates have exceeded the upper limit allowed by the Food and Agriculture Organization FAO in its report at 1989 and all study areas, including the main water reservoirs as values ranging from ( 372.3 Imam Qasim area and 400 Wasti area) $\mathrm{Mmohsm} / \mathrm{cm}$ ( Figure 4 ) in with a decline slight declination from what water source of values shown for the delivery of electrical proving a defect in the treatment of electrical conductivity of water intended for human consumption, It indicates the researcher [19] that high electrical conductivity values may cause diseases to its users Electrical conductivity values are closely correlated with dissolved solids, suspended materials and chlorides .

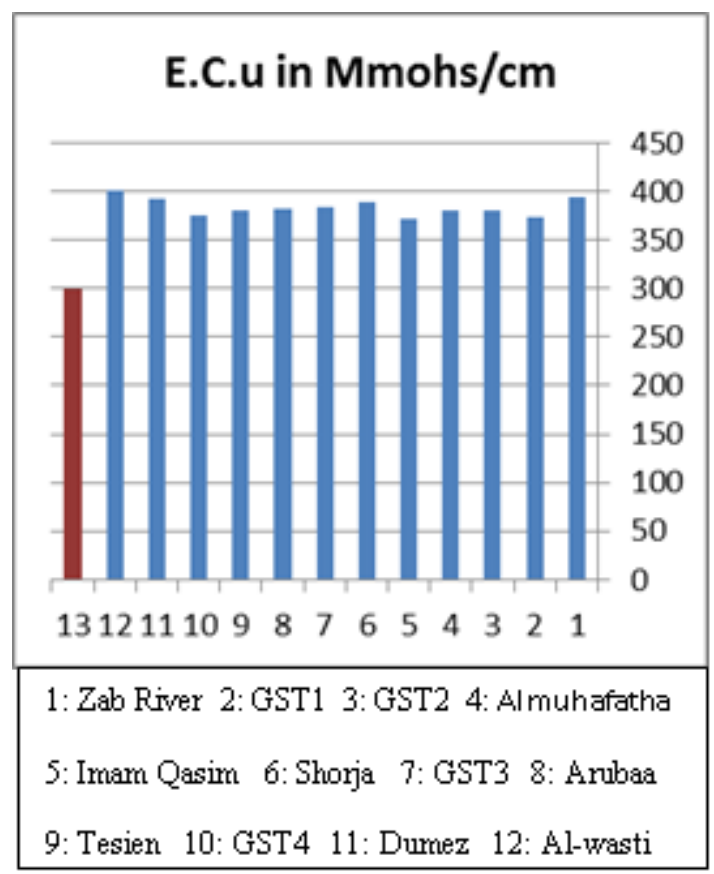

Figure 4 : E.C.u in Mmohs/cm for water samples tested.

The Values of T.D.S. for Source water were $245.5 \mathrm{mg} /$ 1, in the main collection tank $239.1 \mathrm{mg} / \mathrm{L}$, the values of the residential sampling areas for T.D.S. were not significantly different from the values of the main collection tank water after treatment and source water this may be due to the lack of salinity treatment units, or lack of focus on the fact that the water is not salty and well below the permissible limit allowed by ( IBWA and WHO ).

The percentage of total suspended solids in raw water was $47.25 \mathrm{mg} / 1$ with a significant difference of 17.97 $\mathrm{mg} / 1$ from its share in the source water of $65.22 \mathrm{mg} / 1$ . This is due to the disappearance of these particles. It was observed that this percentage was reduced in the collection tanks at most of sampling the times as a result of deposition.

Table 2 shows a difference in the ratio of suspended materials between regions. This may be due to the rapid flow of water inside the pipes, on the one hand, and the rapid supply of water to the residential areas from the collection tanks without leaving a time period on the other hand. The presence of dilutions in the joints of the conveyor tubes may be another cause of the variation.

Total Hardness known as a group of total salts of carbonates, bicarbonates, sulfates, chlorides, calcium nitrate and magnesium. Tables ( 2 ) showed that the total hardness rates did not exceed the permissible limit for the water consumed and for all the sampling areas. The value ranged from (163.7 to 172.1) $\mathrm{mg} / 1$. It was noticed that no significant change in the value of the source water after entering the treatment unit and then 
to the reservoirs of the main city of Kirkuk and to the consumer except for some fluctuations that may be resulted from the interaction of water with the contents of the pipes from the material of sediment or contact with the external soil in the sites of discord within the conveyor tubes and this is consistent with [9] and [13] There is an additional cost for it.

The results of Alkalinity as $\mathrm{CaCo}_{3}$ Table (2) showed alow rates within the specified percentage of water content allowed for human consumption. No significant differences were observed between the sampling sites of the residential areas and the water reservoirs and the main source of feed for the project ( Figure 5 ).

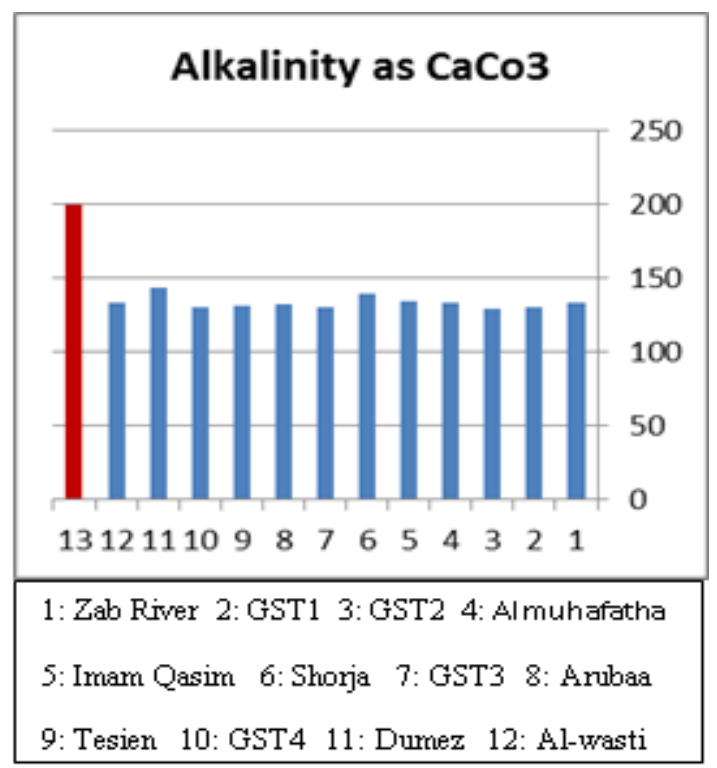

Figure 5 : Alkalinity as $\mathrm{CaCo}_{3}$ for water samples tested

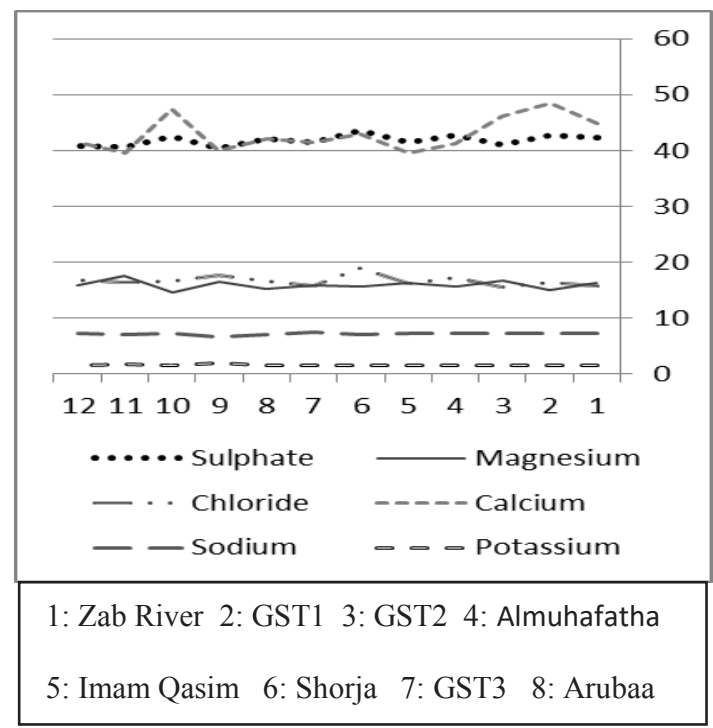

Figure $6: \mathrm{Ca}^{+}, \mathrm{Mg}^{+}, \mathrm{Cl}^{-}, \mathrm{So}_{4}{ }^{\circ}, \mathrm{Na}^{+}$and $\mathrm{K}^{+}$rates for water samples tested .

Positive ions ( Magnesium, Chloride, Sulphate, Sodium and potassium ) all showed low rates within the specified percentage of the permitted water content for human consumption ( IBWA \& WHO ), also there are no significant differences observed between the sampling sites of the residential neighborhoods and the water reservoirs and the main source of feed for the project.

\section{Conclusions}

The water samples taken from the collection tanks for the treated water are pure and confirm the approved standard specifications. It should be noted here that the raw water is of acceptable quality in most physical properties and does not require the material cost and time for treatment.

The periodic distribution of water in most areas of Kirkuk led to a high rate of turbidity and caused damage to the distribution networks, which in turn reflected on the quality of water transferred.

Pollution in the water supplied to some areas are due to the existence of construction and excavations and lack of coordination with the competent authorities on this subject.

Non-maintenance and replacement of old pipes has a reflection on the quality of water supplied to those areas.

\section{Recommendations}

Based on the results of this study, the following are recommended:

- Maintenance and cleaning of liquefaction networks and reservoirs on a regular basis.

- Replacement of some old and old-fashioned pipes with high-quality annealing pipes.

- Pre-coordination between companies and departments responsible for excavation works and Kirkuk water department to prevent the occurrence of excesses on the pipelines.

- Communicate the areas equipped with clean drinking water within the approved standards of nonconsumption of cash to buy bottled water and reduce the use of excess water.

\section{References}

1. Weifeng Li, Wencui Ling, Suoxiang Liu, Jing Zhao, Ruiping Liu, Qiuwen Chen, Zhimin Qiang, and Jiuhui Qu ( 2011) . Development Of Systems For Detection, Early Warning, And Control Of Pipeline Leakage In Drinking Water Distribution. A case study . Journal of Environmental Sciences 2011, 23(11) 1816-1822. 
2. Hossein Shamsaei, Othman Jaafar, Noor Ezlin Ahmad Basri ( 2013 ) . Disadvantage Pressure Changes on the Decline of Water Quality in Water Distribution Systems . Engineering, 2013, 5, 97-105.

3. Grabińska A. Łoniewska, T. Koniłłowicz-Kowalska , G. Wardzyńska and K. Boryn (2007) . Occurrence Of Fungi In Water Distribution System . Polish J. of Environ. Stud. Vol. 16, No. 4 (2007), 539-547.

4. Hem Lars J. and Ingun Skjevrak ( 2002). Potential Water Quality Deterioration Of Drinking Water Caused By Leakage Of Organic Compounds From Materials In Contact With The Water . Proceedings, 20 th NoDig conference, Copenhagen May 28-31 2002.

5. Cerrato José Manuel ( 2005 ) . Impact Of Piping Materials On Water Quality In Tegucigalpa, Honduras . Master of Science in Environmental Engineering . September 5, 2005 , Blacksburg, Virginia . USA.

6. M. Sadiqa, T.H. Zaidia, H. Al Muhannaa \& A.A. Miana ( 1997 ) . Effect Of Distribution Network Pipe Material On Drinking Water Quality . Journal of Environmental Science and Health . Part A: Environmental Science and Engineering and Toxicology .Volume 32, Issue 2, 1997.

7. Timothy Heim , ( 2006 ). Impact Of Polymeric Plumbing Materials On Drinking Water Quality And Aesthetics . (master thesis), April 26th, 2006. Blacksburg, Virginia, USA.

8. Ahn Jeahwan, Hyondong Lee, Seoku Kim, Pilijae Kwak , and Jooyeon Lee ( 2010 ). Corrosion Control Of Drinking Water Copper Pipe By Corrosion Inhibitor . materials science forum . vol. 658.2010 pp. $320-323$.

9. Chen Q W, Qu J H, Liu R P, Li W F.(2008) . RuleBased Model For Aging-Induced Leakage From Water Supply Pipe Network In Beijing City. China Water \& Wastewater, 24(11): 52-56.

10. Nkanga Enefiok J. ( 1980 ). Investigations Of PipeBorne Pollution In Benin City, Nigeria . Water, Air, and Soil Pollution. December 1980, Volume 13, Issue 4, pp 425-437.

11. Scholten Frans and Mannes Wolters (2011). Physical Ageing Of U-P.V.C. Gas And Water Pipes
PVC 2011, 12-14 April 2011, Brighton, UK, British Plastics Federation.

12. Rubeiz C. ( 2010 ), Impact Off Potable Water Disinfectant Of PE Pipe . Jana Laboratories Inc. 280B industrial Pkwy S Arora Ontario, L4G, 3T9 . www.janalab.com.

13. Avhad, Priyanka T. ( 2016 ) . To Study Management and Monitoring of Water Pipeline. International Journal of Innovative Research in Computer and Communication Engineering . Vol. 4, Issue 4, April 2016.

14. Page, A.L. ( 1982 ). Methods Of Soil Analysis, Agron.9, part 2:Chemical and Mineralogical Properties, 2nd ed.,Am. Soc. Agron, Madison, WI, USA(1982).

15. Wahab. Yousri Shehab, Abtasam Hoppe, Amal Francis, Ali Zubair Khalaf (2000). Analytical Guide To The Water Testing Unit. North Oil Company Publications - Fields Authority.

16. IBWA ( 2012 ). Bottled Water Code of Practice, International Bottled Water Association 1700 Diagonal Road, Suite 650 Alexandria, VA 22314 , (703) 683-5213, http://www.bottledwater.org.

17. WHO ( 2006 ) . A Compendium Of Drinking-Water Quality Standards In The Eastern Mediterranean Region. World Health Organization Regional Office for the Eastern Mediterranean Regional Centre for Environmental Health Activities -CEHA.

18. FAO ( 1989 ) . Water Quality For Agriculture . Food and Agriculture Organization of the United Nations Rome, 1985 ㅇ FAO.

19. Al-Hayani AG (2009) . Evaluation Some Groundwater Wells Of Khaffjiyia Village In AlAnbar Governorate. J. Al-Anbar Univ. Pure Sci 3, (no2):30-38, Arabic. 